\title{
Effect of Nursing Instructions for Asthmatic Patients on Local Side Effects of Inhaled Corticosteroids
}

\author{
Heba Sayed Mohammed ${ }^{1}$, Esmat Sayed Abd El-mageed ${ }^{2}$ \& Shaymaa Sayed Khalil ${ }^{3}$. \\ ${ }^{1 .}$ Nursing specialist in El Badary Hospital, Assiut, Egypt. \\ 2. Assistant Professor of Medical Surgical Nursing Faculty of Nursing, Assiut University, Egypt. \\ ${ }^{3 .}$ Lecturer of Medical Surgical Nursing Faculty of Nursing, Assiut University, Egypt.
}

\begin{abstract}
Background: Asthma is a chronic respiratory disease characterized by recurrent attacks of breathlessness and wheezing which vary in severity and frequency from person to person. Aim of the study: To evaluate the effect of nursing instructions for asthmatic patients on minimizing local side effects of Inhaled Corticosteroids (ICS). Research design: Quasi experimental (pre - posttest) research design was utilized to conduct this study. Setting: The study was conducted at internal medical unit of Al-Badary Central Hospital, Assiut, Egypt. Sample: 90 males and females adult patients with asthma receiving ICS. Tools of data collection: Tool (I) Patient assessment sheet and Tool (II) Local side effects assessment sheet. Results: Most of the studied patients, (90.0\%) had a poor level of knowledge about asthma. A significant decrease in local side effects of ICs; hoarseness, dysphonia, dry, sore throat, throat clearing, thirst, and dry cough, among the studied patients after implementation nursing instructions than before (p. < 0. 01). Conclusion: Implementation of the nursing instructions for asthmatic patients had a positive effect on minimizing the many local side effects of ICS as hoarseness, dysphonia, dry, sore throat, throat clearing, thirst, and dry cough. Recommendation: The booklet should be available for nursing team to increase their awareness and to provide patients with sufficient information for decreasing local side effects of ICS.
\end{abstract}

\section{Keywords: Asthma, ICS, Local Side Effects \& Nursing Instructions.}

\section{Introduction}

Asthma affects an estimated 300 million individuals worldwide. It is a serious global health problem affecting all age groups, with increasing prevalence in many developing countries, rising treatment costs, and a rising burden for patients and the community. Asthma still imposes an unacceptable burden on health care systems, and on society through loss of productivity in the workplace and, especially for pediatric asthma, disruption to the family (WHO, 2020).

Asthma causes symptoms such as wheezing, shortness of breath, chest tightness and cough that vary over time in their occurrence, frequency and intensity. Risk factors for developing asthma are a combination of genetic predisposition with environmental exposure to inhaled substances and particles that may provoke allergic reactions or irritate the airways, such as indoor allergens (for example, house dust mites in bedding, carpets and stuffed furniture pollution and pet dander) outdoor allergens (such as pollens tobacco smoke, chemical irritants in the workplace, and air pollution) (GINA, 2020).

Corticosteroids are the first-line the mainstay treatment and the most effective treatment for asthma recommended by the Global Initiative Asthma Guidelines (GINA). ICS improve lung function and quality of life, reducing asthma symptoms, disease progression, and related mortality (Kim et al., 2019). ICS can cause local and systematic adverse effects. Systematic side effects are adrenal suppression, cataracts, fractures and diabetes, the systematic side effect depended on the amount of drug absorbed in to circulation. The common local side effects are from frequent use of ICS for longer period and high does as hoarseness, dysphonia, dry, sore throat, throat clearing, candidiasis, sensation of the thirst, tongue hypertrophy, perioral dermatitis, pharyngitis, and dry cough (Hassen \& Abo Hasseba., 2016).

Nurses play a vital role in asthma management and perform a variety of vital functions in asthma care, including asthma education in the primary care setting and in hospitals. Nurses are at the front line of asthma management, and have the crucial role of early identification and management, also obtain information on how asthma affects patient's every day activities and self-concept, and educate patients about adverse effects result from use of ICS. It is the nurse duty to give correct and current information and remove barriers to care. Nurse has the responsibility to assess symptoms control, safe medication use and correct any information (Yousif et al., 2020). Significance of the study

Prevalence of asthma in Egypt 6.7\% (Tarraf et al., 2018) while the prevalence of asthma among 
secondary school student In Assiut district was $8.7 \%$ (Sanousy et al., 2018). In El Badary Hospital, the average of asthmatic patients who admitted for treatment with inhaled corticosteroid was about 350 patients (El-Badarey Hospital information center record, 2016 -2018). From the researcher's clinical experience it has been observed that most asthmatic patients who treated with ICS complain from local side effects and they haven't enough knowledge to reduce those side effects so, this study was conducted to provide nursing instructions for asthmatic patients who treated with ICS to minimize their local side effects.

\section{Aim of the study}

To evaluate the effect of nursing instructions for asthmatic patients on minimizing local side effects of inhaled corticosteroids.

\section{Patients \& Methods}

\section{Research design}

Quasi-experimental research (pre-post) one group test was used in this study.

\section{Study variables}

The independent variable in this study was the nursing instructions for asthmatic patients while the dependent variable was local side effects of inhaled corticosteroids.

\section{Setting of the study}

The study was conducted at internal medical unit of Al-Badary Central Hospital, Assiut, Egypt.

\section{Study sample}

A sample of 90 Asthmatic patients undergoing treatment with inhaled corticosteroids were included in this study. Their ages ranged between (18-65) years, from both sexes, and were willing to participate in this study.

\section{Sample size}

The sample was selected by using the following equation according to Steven K. Thompson (2012):

$$
n=\frac{N \times p(1-p)}{\left.\left.\llbracket N-1 \times\left(d^{2} \div z^{2}\right)\right]+p(1-p)\right]}
$$

- $\mathrm{N}=$ total patient population size of 350 who treated with ICS at El-Badary hospital during years (20162018).

- $\mathrm{Z}=$ confidence levels is 0.95 and is equal to 1.96

- $\mathrm{D}=$ The error ratio is $=0.05$

- $\mathrm{P}=$ The property availability ratio and neutral $=0.5$

Tools of data collection

Two tools were utilized to collect pertinent data for this study:

Tool I: Patient assessment sheet

It was developed by the researcher based on literature review. This tool consisted of three parts:
(I) Patients' demographic characteristics: It was developed to assess demographic characteristics as age, sex, educational level, marital status, occupation, residence, and family history.

(II) Patient clinical data: It included asthma duration, ICS duration, presence of other chronic diseases, taking other medications and smoking.

(III) Patient's knowledge It was developed to asses patient knowledge about asthma, action of ICS, correct use of ICS, the local side effects of ICS, and dealing with local side effects of ICS.

Scoring system:

Total number questions of were 6 list questions, 2 grades awarded for the complete correct answer, 1 grade for the incomplete correct answer and zero for the incorrect answer. Total score was 12 degree.

Total knowledge score categorized in to 3 categories (onianwa et al, 2017).

$\begin{array}{ll}\text { - } \geq 75 \% & \text { Good level } \\ \text { - } \quad 50 \% \text { to } 75 \% & \text { Fair level } \\ \text { - } \quad<50 \% & \text { Poor level. }\end{array}$

Tool II: Local side effects assessment sheet:

It included 10 local side effects of ICS might occurred for asthmatic patient receiving ICS.

Scoring system

The researcher asked about the presence of each side effect of ICS. Each question has four responses from 1: 4

Never $=1$ Sometimes $=2$ Often $=3$ Always $=4$

Developed nursing instructions for asthmatic patients:

The instructions were developed by the researcher after reviewing current national and international literature according to patients' needs. These instructions aimed to help in reducing local side effects of ICS. The developed nursing instructions consisted of three parts: First part involved knowledge about asthma, ICS and local side effects of ICS. Second part involved nursing instructions about how to prevent asthma attack and correct methods of using a spacer or holding device. The third part involved nursing instructions about prevention of local side effects of ICS by gargling with water and how to deal with each local side effects of ICS as nursing instructions for hoarseness, dysphonia, dry, sore throat, throat clearing, candidiasis, sensation of the thirst, tongue hypertrophy, perioral dermatitis, pharyngitis, and dry cough.

\section{Methods}

\section{Ethical considerations}

The study followed the common ethical guidelines of clinical research according to the principles of Helsinki Declaration, (1996) for medical research. The research proposal approved from 
Ethical committee in the Faculty of Nursing, which included:

1. There was no risk for study subject during application of the research.

2. Oral consent was obtained from all patients who were participating in the study, after explaining the nature and purpose of the study.

3. Confidentiality and anonymity was assured.

4. Study subject had the right to refuse to participate and or withdraw from the study without any rational any time.

5. Study subject privacy was considered during collection of data.

\section{Face validity}

It was established by panel of five expertise (Medical and Nursing) who reviewed the tools for clarity, relevance, comprehensiveness, understanding, applicability and easiness for administrative, minor modifications were required.

Test reliability of the proposed tools were ascertained with cronbach's alpha $=0.88$ and 0.76 .

\section{Pilot study}

A pilot study was done on $10 \%$ (9 patients.) of the sample Test clarity and feasibility of the developed tools. Also, it provided an estimate of time needed to fill out the tools. There was no modification so the pilot study sample added to whole study sample.

\section{Procedure}

The study proceeded using the following phases:

Preparatory phase:

- An official approval to carry out the study obtained from the dean of Faculty of Nursing, Assiut University to the manger of El-Badary hospital.

- An official approval for data collection obtained from administrator of the El-Badary Hospital.

- The researcher met the selected patients; each patient was fully informed with the purpose and nature of this study and the informed consent was obtained from the patients. Base line data were collected by researcher using tools (I and II).

Implementation phase

- Data were collected during the period from January to July2019,

- The studied patients were given an educational colored booklet in clear Arabic language; which included nursing instructions for asthmatic patient in one session.

- Each session included 2 patients, and took about 40-60 minutes.

- The study was carried out daily except on Friday in the morning shift at medical department.

- At the end of the session, there was 5-10 min for discussion \& feedback.
- The researcher used pictures, diagram, and role play to help them retain the learned material then give them a copy of the illustrated booklet.

- The researcher arranged with the patients the time and place for follow up after 6 weeks in the medical unit in El-Badary Hospital.

- The researcher ensured commitment of the patients to follow the nursing instructions weekly by telephone call once weekly.

\section{Evaluation phase}

- In this phase, the studied patients were reassessed after 6 week using (tool II) to evaluate the effect of implementing the nursing instructions on local side effects of ICS for asthmatic patients (presence and absence).

- The session took approximately 15 minutes in the previous mentioned setting.

\section{Statistical design}

Statistical analysis all the analyses were performed using SPSS (IBM version 22.0). To analyze the general data of subjects the researchers used the descriptive statistics and constituent ratio. For analyzing the occurrence side effects and patients knowledge scores the researchers utilized the Pearson chi-square and the paired t- tests. All p. values were two-tailed, and the significance level considered < 0.05 . 


\section{Results}

Part (I): Demographic characteristics of the studied patients.

Table (1): Frequency distribution of demographic characteristics of the studied patients $(n=90)$.

\begin{tabular}{|c|c|c|c|}
\hline \multicolumn{2}{|c|}{ Demographic characteristics } & N. & $\%$ \\
\hline \multirow{6}{*}{ - Age } & $18<25$ & 10 & 11.1 \\
\hline & $25<35$ & 12 & 13.3 \\
\hline & $35<45$ & 26 & 28.9 \\
\hline & $45<55$ & 19 & 21.1 \\
\hline & $>55$ & 23 & 25.6 \\
\hline & mean $\pm \mathrm{SD}$ & \multicolumn{2}{|c|}{$34.8 \pm 12.6$} \\
\hline & Male & 50 & 55.6 \\
\hline - Sex & Female & 40 & 44.4 \\
\hline \multirow{6}{*}{ - Level of Education } & not educated & 19 & 21.1 \\
\hline & read and write & 22 & 24.4 \\
\hline & Primary & 9 & 10.0 \\
\hline & Preparatory & 10 & 11.1 \\
\hline & Secondary & 8 & 8.9 \\
\hline & University & 22 & 24.4 \\
\hline \multirow{4}{*}{ - Marital status } & Single & 10 & 11.1 \\
\hline & Married & 63 & 70.0 \\
\hline & Divorced & 1 & 1.1 \\
\hline & Wideow & 16 & 17.8 \\
\hline \multirow{7}{*}{ - Occupation } & Not work & 11 & 12.2 \\
\hline & Farmer & 21 & 23.3 \\
\hline & Student & 6 & 6.7 \\
\hline & Employee & 15 & 16.7 \\
\hline & House wife & 23 & 25.6 \\
\hline & Carpenter & 8 & 8.9 \\
\hline & Painter & 6 & 6.7 \\
\hline \multirow{2}{*}{ - Residence } & Urban & 35 & 38.9 \\
\hline & Rural & 55 & 61.1 \\
\hline \multirow{2}{*}{$\begin{array}{ll}\text { - } & \text { Family } \\
- & \text { History }\end{array}$} & Present & 68 & 75.6 \\
\hline & Absence & 22 & 24.4 \\
\hline
\end{tabular}

Part (II): Clinical data of the studied patients.

Table (2): Frequency distribution of the studied patients according to their clinical data $(n=90)$.

\begin{tabular}{|c|c|c|c|}
\hline Clinical data & & $\mathbf{N}$ & $\%$ \\
\hline \multirow{3}{*}{ - Asthma duration } & $<5$ years & 54 & 60.0 \\
\hline & $5<10$ years & 31 & 34.4 \\
\hline & $>10$ years & 5 & 5.6 \\
\hline$-\quad$ mean \pm SD & \multicolumn{3}{|c|}{$5.93 \pm 3.1$} \\
\hline \multirow{3}{*}{ - ICS duration } & 1 year & 54 & 60.0 \\
\hline & 2 years & 31 & 34.4 \\
\hline & 3 years & 5 & 5.6 \\
\hline - Mean \pm SD & \multicolumn{3}{|c|}{$5.92 \pm 3.3$} \\
\hline - Other medications & \multicolumn{2}{|c|}{40} & 44.4 \\
\hline - Smoking & \multicolumn{2}{|c|}{41} & 45.6 \\
\hline
\end{tabular}




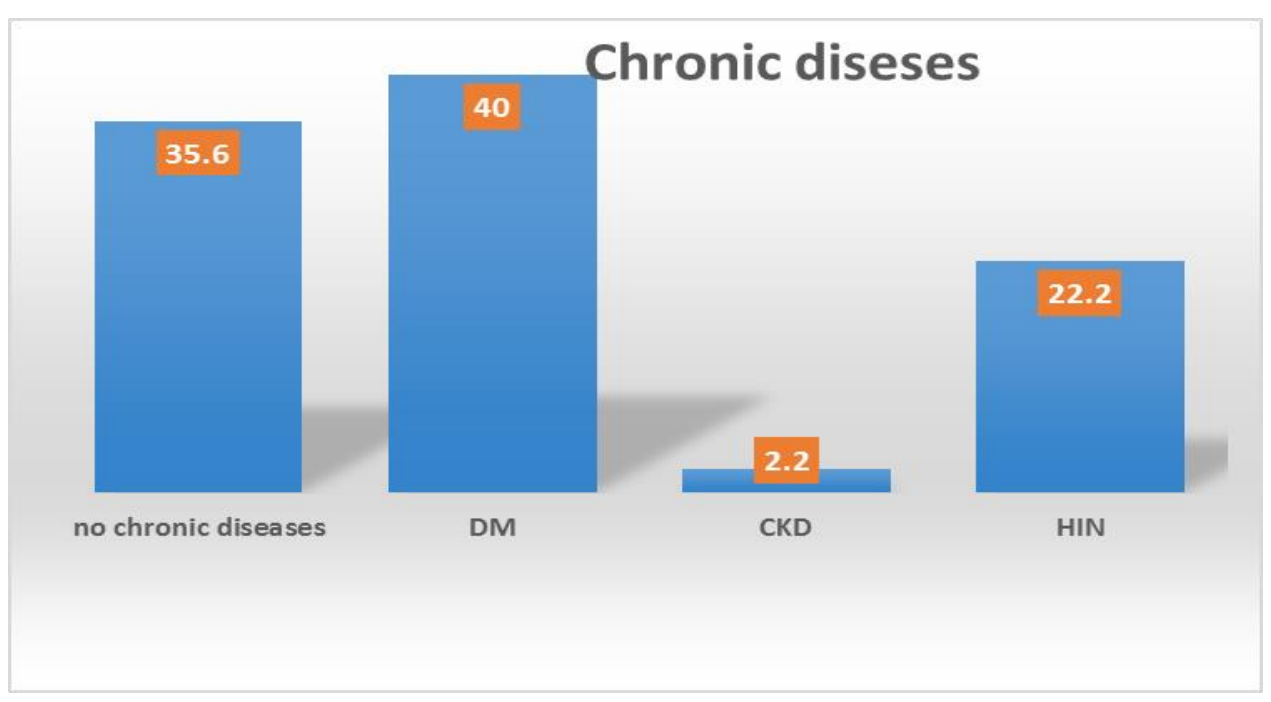

Figure (1): Frequency distribution of studied patients according to Chronic diseases (n=90).

Part (III): Patients' knowledge.

Table (3): Distributions of the studied patients according to their Knowledge about asthma (n=90).

\begin{tabular}{|l|c|c|c|c|c|c|}
\hline \multirow{2}{*}{ Knowledge } & \multicolumn{2}{|c|}{ Correct } & \multicolumn{2}{c|}{ In complete correct } & \multicolumn{2}{c|}{ In correct } \\
\cline { 2 - 7 } & $\mathbf{N}$. & $\mathbf{\%}$ & $\mathbf{N}$. & $\mathbf{\%}$ & N. & \% \\
\hline - Q1: Definition of asthma & 2 & 2.2 & 50 & 55.6 & 38 & 42.2 \\
\hline - Q2: Risk factors of asthma & 1 & 1.1 & 40 & 44.4 & 49 & 54.4 \\
\hline - Q3: Action of ICS & 0 & 0.0 & 16 & 17.8 & 74 & 82.2 \\
\hline - Q4:Correct use of ICS & 1 & 1.1 & 46 & 51.1 & 43 & 47.8 \\
\hline - Q5: Local side effects of ICS & 1 & 1.1 & 40 & 44.4 & 49 & 54.4 \\
\hline $\begin{array}{l}\text { Q6: Deal with local side effects } \\
\text { of ICS }\end{array}$ & 0 & 0.0 & 20 & 22.2 & 70 & 77.8 \\
\hline - Total & \multicolumn{7}{|c|}{ mean \pm SD } \\
\hline
\end{tabular}

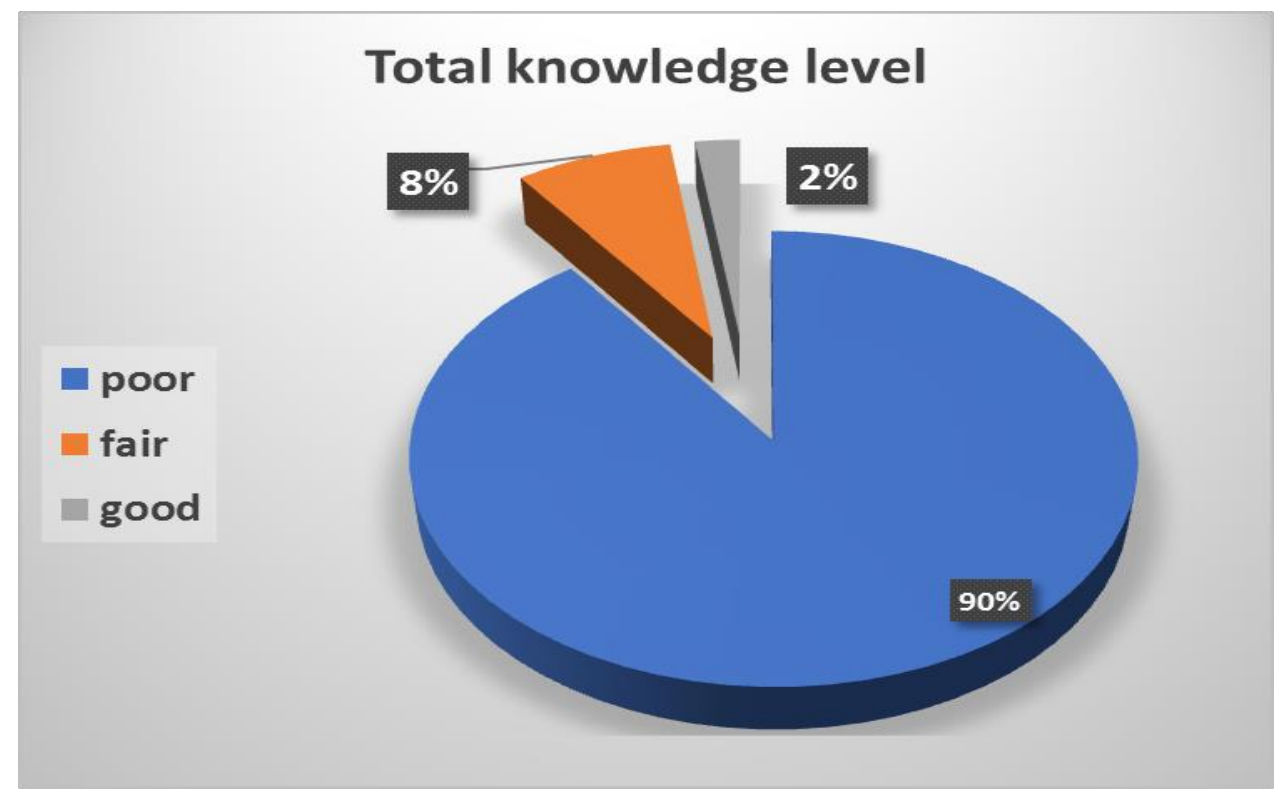

Figure (2): Frequency distribution of the studied patients according to their level of knowledge (n=90). 


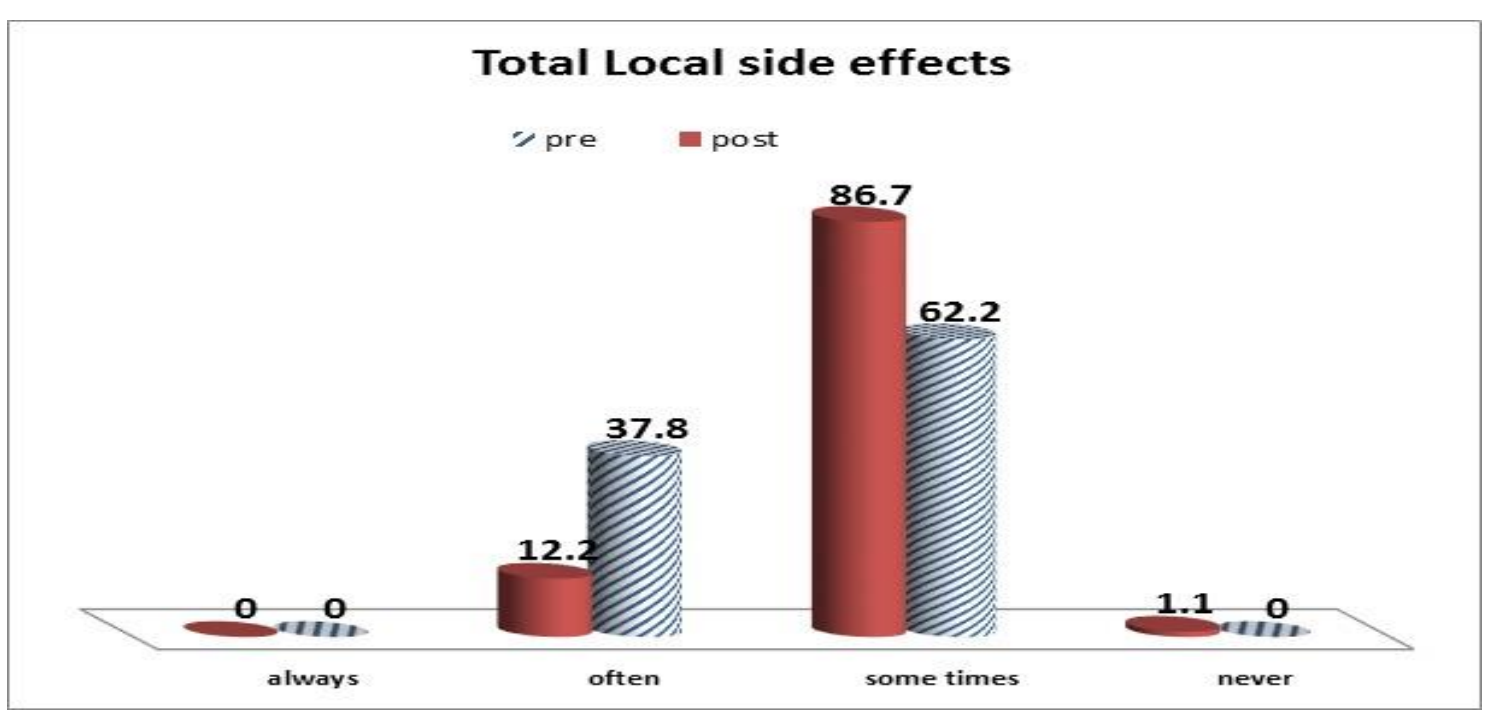

Part (IV) Local side effects of ICS

Figure (3): Comparison between local side effects of ICS pre and post application of the nursing instructions among the studied patient $(\mathrm{n}=90)$.

Table (4): Relationship between demographic characteristics and local side effects of ICs post nursing instructions implementation $(\mathbf{n}=90)$.

\begin{tabular}{|c|c|c|c|c|c|c|}
\hline \multirow{2}{*}{\multicolumn{2}{|c|}{ Demographic characteristics }} & \multicolumn{4}{|c|}{ Local side effect post test } & \multirow{2}{*}{ P. value } \\
\hline & & \multirow{2}{*}{$\frac{\text { Never }}{0}$} & \multirow{2}{*}{$\frac{\text { Some times }}{9}$} & \multirow{2}{*}{$\frac{\text { Often }}{1}$} & \multirow{2}{*}{$\frac{\text { Always }}{0}$} & \\
\hline \multirow{5}{*}{ - Age group } & $18-25$ & & & & & \multirow{5}{*}{$0.001 * *$} \\
\hline & $25-35$ & 0 & 11 & 1 & 0 & \\
\hline & $35-45$ & 0 & 16 & 10 & 0 & \\
\hline & $45-55$ & 0 & 13 & 6 & 0 & \\
\hline & $>55$ & 0 & 7 & 16 & 0 & \\
\hline \multirow{2}{*}{ - Sex } & Male & 0 & 31 & 19 & 0 & \multirow[t]{2}{*}{$0.568 \mathrm{NS}$} \\
\hline & Female & 0 & 25 & 15 & 0 & \\
\hline \multirow{6}{*}{ - Level of education } & Not educated & 0 & 8 & 11 & 0 & \multirow[t]{6}{*}{$0.066 \mathrm{NS}$} \\
\hline & Read and write & 0 & 11 & 11 & 0 & \\
\hline & Primary & 0 & 5 & 4 & 0 & \\
\hline & Preparatory & 0 & 8 & 2 & 0 & \\
\hline & Secondary & 0 & 6 & 2 & 0 & \\
\hline & University & 0 & 18 & 4 & 0 & \\
\hline \multirow{4}{*}{ - Marital status } & Single & 0 & 9 & 1 & 0 & \multirow{4}{*}{$0.172 \mathrm{NS}$} \\
\hline & Married & 0 & 38 & 25 & 0 & \\
\hline & Divorced & 0 & 1 & 0 & 0 & \\
\hline & Wideow & 0 & 8 & 8 & 0 & \\
\hline \multirow{7}{*}{$\begin{array}{c}\text { - Occupational } \\
\text { status }\end{array}$} & Not work & 0 & 8 & 3 & 0 & \multirow{7}{*}{$0.676 \mathrm{NS}$} \\
\hline & Farmer & 0 & 11 & 10 & 0 & \\
\hline & Student & 0 & 5 & 1 & 0 & \\
\hline & Employee & 0 & 9 & 6 & 0 & \\
\hline & House wife & 0 & 13 & 10 & 0 & \\
\hline & Carpenter & 0 & 5 & 3 & 0 & \\
\hline & Painter & 0 & 5 & 1 & 0 & \\
\hline \multirow[b]{2}{*}{ Residence } & Urban & 0 & 28 & 17 & 0 & \multirow{2}{*}{$0.586 \mathrm{NS}$} \\
\hline & Rural & 0 & 28 & 17 & 0 & \\
\hline
\end{tabular}


Table (5): Relationship between local side effects of ICS and medical data of the studied patients post nursing instruction implementation $(\mathbf{n}=90)$.

\begin{tabular}{|l|c|c|c|c|c|c|}
\hline \multicolumn{2}{|c|}{ Medical data } & \multicolumn{4}{c|}{ Local side effect post test } & \multirow{2}{*}{ P. value } \\
\cline { 3 - 8 } & Never & Some Times & Often & Always & \\
\hline - Family history & Present & 0 & 37 & 31 & 0 & $0.006^{* *}$ \\
\hline - Other medication & Present & 0 & 16 & 24 & 0 & $0.001^{* *}$ \\
\hline - HIN & Present & 0 & 6 & 14 & 0 & $0.0001^{* *}$ \\
\hline - CKD & Present & 0 & 1 & 1 & 0 & $0.615 \mathrm{NS}$ \\
\hline - DM & Present & 0 & 15 & 21 & 0 & $0.001^{* *}$ \\
\hline - Smoking & Present & 0 & 24 & 17 & 0 & $0.329 \mathrm{NS}$ \\
\hline
\end{tabular}

Chi-square test Ns: not significant $p .<0.05 \quad * *$ Significant $p .<0.01$ $* * *$ highly significant $p<0.001$

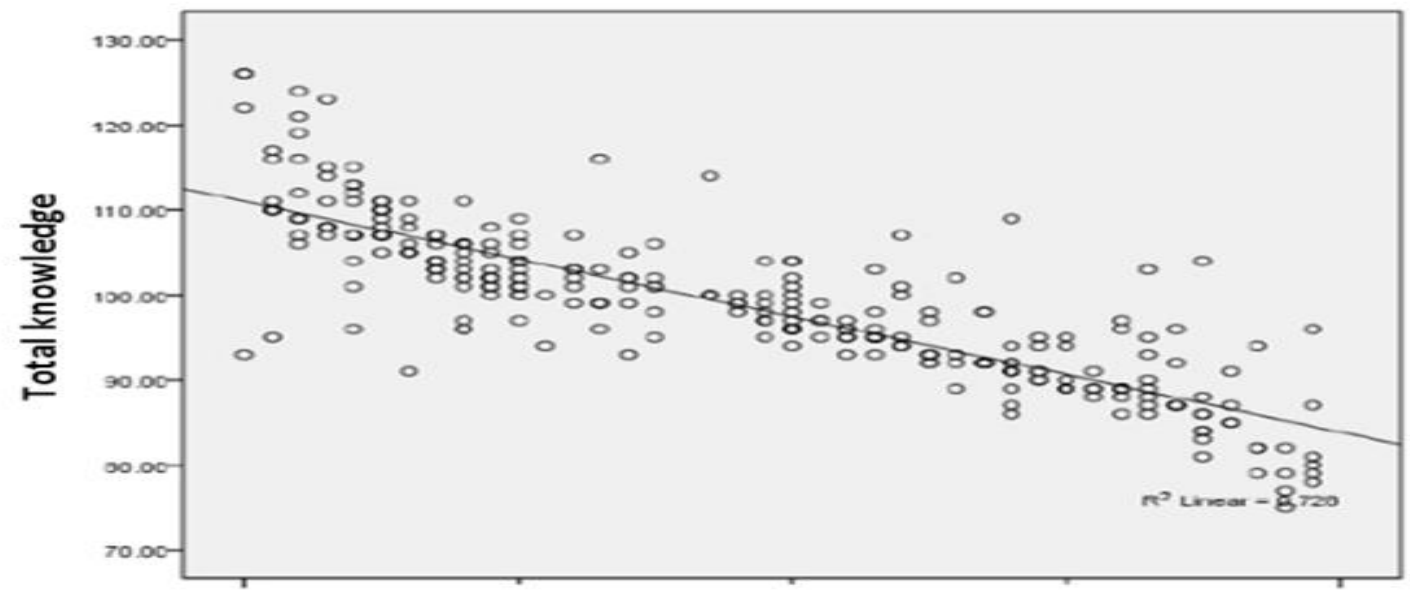

\section{Local side effect post-test}

Figure (4): Correlation between total knowledge score and their local side effects of ICs post implementing the nursing instruction among studied patients $(\mathbf{n}=90)$.

Table (1): Shows that the mean age of studied patient's was $(34.8 \pm 12.6)$. The highest percentage of theme were male $(55.6 \%)$, married, $(70 \%)$, house wife $(25.6 \%)$, from Rural area and had afamily history of asthma (75.6\%).

Table (2): Reveals that the highest percentage of the studied sample $(60 \%)$ suffered from asthma for less than 5 years and treated with for one year. Near half of patients taking other medications $(44.4 \%)$ and smoking (45.6\%).

Figure (1): Shows that two fifth of the studied sample hade diabetes mellitus. (40.0\%), and one fifth $(22.2 \%)$ had hypertension, while (35.6\%) didn't suffer from any chronic diseases

Table (3): Shows that the highest percentage of studied patients their knowledge were incorrect regarding the action of ICS (82.2\%), deal with local sides effect of ICS (77. 8\%) and risk factor of asthma $(54.4 \%)$. The mean knowledge score of the studied sample was $\mathbf{3 . 4} \pm \mathbf{2 . 2}$

Figure (2): Shows that most of the studied patients, (90.0\%) had a poor level of knowledge about asthma.
Figure (3): Significant decrease in the local side effects of ICs (hoarseness, dysphonia, dry, sore throat, throat clearing, thirst, and dry cough) among the studied patients after implementation the nursing instructions than before implementation (p. < 0.01).

Table (4): Shows that there was no statistically significant difference between local side effects of ICS and demographic characteristics of the studied patient post nursing instruction implementation except age group $(\mathrm{p}<0.01)$.

Table (5): Shows that there were statistically significant relations between local side effects and family history, taking other medication HIN and DM among the studied patients $(\mathrm{p}<0.001)$.

Figure (4): There was no correlation between the total knowledge score and local side effects of ICS.

\section{Discussion}

ICS are widely used in asthma and chronic obstructive pulmonary disease (COPD), to improve symptoms. Local adverse effects of ICS include dysphonia, oral candidiasis, reflex cough, and 
bronchospasm. These adverse effects are less common with low-dose ICS than with high-dose ICS (Harper et al., 2019).

Regarding demographic characteristics of the studied patients, the current study showed that the highest percentage of studied patients their age ranged between (35 to 45) years, more than half of them were males, This result agreed with Dawood et al., (2019) who reported that half of their studied participant were males, But these results disagreed with Nafie et al., (2017) who found that majority of studied patients were females. Regarding educational level, about half of studied patients were read and write and had university level of education this result agreed with: Abd El-Wahab et al., (2016) who reported that half of asthmatic patients had a university education level. But, Yilmaz et al., (2016) disagreed with these results and found that, more than half of the sample were graduated from primary schools.

The highest percentage of the study sample were, house wives and farmers which correlated with the nature of the rural areas, as they were mostly exposed to house dust mite, which agreed with Tageldin et al., (2015) who reported that less than half of female asthmatic patients were house wives and one fifth of asthmatic patients were farmers. Also, Shamkuwar et al., (2015) who reported that one third of asthmatic female patients were house wife but one third were retired.

The present study revealed that, more than half of study sample from rural area this result agreed with Amin et al., (2019) who showed that three quarters of their sample were from rural areas, But this result disagreed with Sanousy et al., (2018) who showed that higher prevalence rate of asthma was in urban regions than in rural residence.

Regard clinical data, most of the studied patients of the current study had a family history of asthma this result agreed with Ibrahim et al., (2019) who showed that, near than half of the asthmatic studied patients had a family a history of bronchial asthma. Nevertheless, these results disagreed with Elbanna et al., (2017) who found that more than half of patients with asthma did not have a family history of bronchial asthma.

Regarding health history, the present study showed that the highest percentage of the studied patients were suffered from asthma for less than 5 years and use ICS for 1 year. This result agreed with Baraka et al., (2020) who reported that majority of patients had asthma duration that ranged from 2- 8years. However, these results disagree with Bayomi et al., (2018) who found that the duration of asthma and use ICS was more than ten years.
Regarding smoking, near half of patients with ICS were smokers, this result agreed with Price et al., (2017) who reported that near half of asthmatic patients were current or ex-smokers, however these results disagreed with, Mohamed \& Badran (2016) who revealed that majority of the study participants with asthma had no smoking history.

Regarding chronic disease, the current study revealed that the two fifth of studied patients had DM and on fifth had hypertension this result supported by Ahmed et al., (2020) who demonstrated the highest percentage of the participant had diabetes. While, Mabrouk et al., (2017) found that more than one third of asthmatic patients were hypertensive.

Regarding patients knowledge most of studied patient's had a poor level of knowledge about asthma and ICS. From the researchers' point of view, this may be due to lack of provided knowledge given to this group of patients .Also, highest percentage of patient had low level of education. These had a great effect on their total level of knowledge. This result agreed with Nguyen, et al., (2018) who revealed that majority of the study participants with asthma their general knowledge about asthma and selfmanagement of asthma were low.

Mohamed et al., (2020) agreed with the current study results they found that implementation of educational program had a positive effect on improving the asthmatic patients' knowledge, practices and self-management.

Regarding local side effects of ICS, the result of the present study showed significant decrease in local side effect of ICS (hoarseness, dysphonia, dry, sore throat, throat clearing, thirst, and dry cough) among the studied patients after implementation the nursing instruction than before implementation.

This result may be due to application of nursing instructions which helped in reducing the local side effects of ICS, as the nursing instruction included knowledge about the correct methods of using a spacer or holding device, prevention of local side effects of ICS by gargling with water to decrease drug depositions, and how to deal with each side effect. Also using pictures, diagram and role-play with discussion during teaching sessions helped the patients to retain the learned material in addition to follow up by the researchers through telephone to ensure the patients' compliance to implement the nursing instructions played an important role in reducing the local side effects of ICS.

In this regard, Hashim et al., (2019) stated that saltwater gargles can be an effective way to relieve discomfort from sore throat. Saltwater gargles are easy and cheap to make, Water temperature, as desired, lukewarm water or hot water. Also Hassen \& Abo Hasseba, (2016) reported that the asthmatic 
patients were instructed to rinse their mouth with water after using ICSs to decrease the chance of having oral candidiasis. Congruent with the current study, Yılmaz et al., (2016) reported that asthmatic patients using ICS should be advised to rinse out their mouth with water, spitting out the rinse, and brush their teeth after using their device, which reduce the risk of developing a sore throat or hoarseness, in their study about the effect of a training program on oral health and behavior change in asthma patients.

In the same line, Nikolaos et al., (2016) concluded that rinsing the mouth and the oropharynx by gargling with water immediately after the use of inhaler to remove the locally deposited amount of steroid in the mucosa reduced the risk of developing a sore throat or hoarseness in their study about the new inhaled corticosteroids and voice problems.

\section{Conclusions}

Most of the studied patients had a poor level of knowledge about asthma. The nursing instructions for asthmatic patient had appositive effect on minimizing the local side effects of ICS.

\section{Recommendation}

The study recommended that Based on the results of the present study:

1. Patient should be provided with sufficient information about asthma and adverse effects result from use of ICS before discharge from the hospital.

2. Periodic monitoring of nurses, knowledge about asthma and ICS and practice to evaluate the level knowledge of nurses working in chest department.

3. Booklets should be available and distributed for nursing team to increase their level of knowledge and to provide patient with sufficient information for decreasing local side effects of ICS.

4. Replication of the study on a larger sample from different geographical area in Eygpt.

\section{References}

- Abd El-Wahab, E., Farag, H., El-Nimr N., \& ElDein H., (2016): Asthma Triggers and Control among Adults in an Egyptian Setting. J Pulm Med Vol.(1), No.(1), 56-67

- Ahmed W., Mohammed G., \& Abd Elmageed, E., (2020): Effect of an Educational Nursing Program on Patients' Adherence to Drugs, , Nicotine Dependency and Degree of Asthma Control among Asthmatic Patients American Journal of Nursing Research, Vol.(8), No.(1), 8190.

- Amin M., Shafik S., \& Fouad A., (2019): Quality of life Among Elderly People with Bronchial
Asthma in Beni-Suef CityJournal of Nursing and Health Science, Vol.( 8), No.(5), 01-15

- Bayomi R., Taha N., Zatton H., \& Elshora A., (2018): Effect of Nursing Intervention Program on Nurses Knowledge, Practices and Patients Outcomes with Bronchial Asthma Journal of Nursing and Care Vol.(7), No.(2), 2 -6

- Baraka M., EIDessouky H., Khamees A., Abd ElFattah A., \& Ezzat E., (2020): Voice changes associated with inhaled steroids On obstructive lung disease patients. Journal of Otolaryngology Vol.(12), No.(1), 1-7

- Dawood A., Singh K., Minarey N., Singh H., \& Shrivastava, N., (2019): Assessment of quality of life in asthmatic patients on inhaled corticosteroids: an observational study. International Journal of Contemporary Medical Research Vol.(6), No.(4), 15.

- Elbanna R., Sileem A., Bahgat S., \& Ibrahem G., (2017): Effect of bronchial asthma education program on asthma control among adults at Mansoura district Egyptian Journal of Chest Diseases and Tuberculosis Vol.(66), No.(4), 561569.

- Global Initiative for Asthma. (2020): Global strategy for asthma management and preventionfor adults and children older than 5 years www.ginasthma.org

- Hassen H., \& Abo Hasseba M., (2016): Voice evaluation in asthma patients using inhaled corticosteroids Vol.(2 6), No.(2), 101-108

- Hashim A., Mohammed, M., Abd Al mageed, A., (2019): designing nursing recommendations for patients with chronic bronchitis Assiut Scientific Nursing Journal Vol , (7) No (16), 1-7

- Harper J., Beasley R., Bird G., Maijers I., \& Weatherall M., (2019): Inhaled Corticosteroid Therapy in Adult Asthma. Time for a New Therapeutic Dose American journal, Respiratory and Critical Care Medicine vol (119) No (12), 1471-1477

- Ibrahim D., hahin E., \& Abdelkadr H., (2019): Effect of an Educational Program Regarding Self Care Management Behaviors for Patients with Bronchial AsthmaPort Said Scientific Journal of Nursing Vol.(6), No.(2),1-21

- Kim M., Rhee C., Shim J., Park S., Yoo K., Kim, B., Bae, H., Sim Y., \& Lee, J., (2019): Inhaled Corticosteroids in Asthma and the Risk of Pneumonia. Allergy Asthma Immunol Resarch Vol , (11) No, (6), 795

- Mohamed, H., Farahat, T., Hegazy, N., \& Ali, A., (2020): Outcome of An Educational Program on Bronchial Asthma Self-Management The Egyptian Journal of Hospital Medicine Vol. 81 (3), 1699-1703 
- Mabrouk A, Abd El-Aziz A, Agha M., \& Kashlana D., (2017): Study of demographic and clinical characteristics of bronchial asthma patients in Mahalla Chest Hospital Menoufia Medical Journal, Vol (30), No. (1), 241-248

- Mohamed W., \& Badran H., (2016): SelfManagement Program to Improve Asthma Knowledge and Inhaler Technique among Adult with AsthmaIOSR Journal of Nursing and Health Science Vol (5), No. (2), 37-47

- Nafie R., Mohamed M., Elhawarya A., \& ElShelkamy H., (2017): Assessment of bronchial asthma management among adult patients in Chest Department of Zagazig University Hospitals Egyptian Journal of Chest Diseases and Tuberculosis Vol, (66), No. (2), 197205

- Nikolaos S., Kopoulos A., Anastasia B., \& Eirini D., (2016): Inhaled Corticosteroids and Voice Problems. What Is New? Journal of Voice vol, (31), No. (3), 1-6

- Nguyen V., Huynh Th, and NChavannes (2018): Knowledge on self-management and levels of asthma control among adult patients in $\mathrm{Ho}$ Chi Minh City, Vietnam. International Journal of General Medicine, (11), No. (2), 81-89

- Onianwa P., Aonge T., Otegbayo J., Ike E., Chukura F., Are O., Akani O., Ayorinde M., Dubi I., \& Yaya O., (2017): Pain as 5th sign, Impact of painassessment training program on Nigerian nurses knowledge of pain management, International Nursing and midwifery, vol (9) No, (11), 129-135.

- Price D, Rodríguez M., Ryan D., Lavorini F., \& Haughney, J., (2017): Inhaler Errors in the CRITIKAL Study: Type, Frequency, and Association with Asthma Outcomes Journal ALLERGY CLIN IMMUNOL PRACT vol (5), No. (4), 1071-1081.

- Sanousy K., Fathy M., Saleh M., \& Elsayed R., (2018): Bronchial Asthma in Secondary School Students in Assiut". EC Paediatrics vol (7), No. (9), 884-897.

- Shamkuwar, C., Kumari, N., Meshram, S., Dakhale, G., \& Motghare, V., (2015) Evaluation of Knowledge, attitude and medication adherence in asthma Journal of Young Pharmacists, Vol, (8), No. (1), 39-43

- Steven K. Thompson ( 2012): Sample size, 59-60

- Tarraf, H., Aydin, O., Mungan D., Albader, M., Mahbouo, B, Dodle A., Lahlou A., Tariq L., Aziz F., \& El Hasnaoui, A., (2018): Prevalence of asthma among the adult general population of live middle eastern https://www.medicalnewstoday.com/articles/32566 6.php
- Tageldin M., Wagih K., \&Maher O., (2015): Study the pattern of bronchial asthma among outpatients clinic at Sohag and Akhmeem Chest Hospitals Egyptian Journal of Chest Diseases and Tuberculosis Vol (64), No. (2), 313-323

- World Health Organization, (2020): Chronic respiratory diseases Causes of asthma https://www.who.int/

- Yılmaz, F., Çınar, S., Yılmaz, A., \& Kumsar A., (2016): The Effect of a Training Program on Oral Health and Behavior Change in Asthma Patients Balkan Medical Journa; vol 33(4), 411-418.1

- Yousif, N., El Shinawy, O., Abd El Mageed. E., \& El-Shafiey F., (2020): Designed Education Program for Nurses about Immediate and Long Term Nursing Management of Patient with Status Asthmatic, Assiut Scientific Nursing Journa Vol , (8) No, (20), 141-154 